\title{
PROBLEMAS Y PERSPECTIVAS DE LA FILOSOFÍA COMO DIÁLOGO INTERCULTURAL
}

\author{
Ricardo Salas Astrain \\ Universidad Católica Silva Henríquez. Santiago. Chile
}

\section{RESUMEN}

La tesis central de este artículo busca demostrar que, vinculando entre sí algunos conceptos provenientes de dos corrientes filosóficas contemporáneas que asumen el linguistic turn, i.e., la hermenéutica y la pragmática del discurso, puede avanzarse en el esbozo de una teoría de la acción intersubjetiva, de tipo intercultural. Ambas perspectivas tienen una categoría fenomenológica central en su base que es la del mundo de la vida corriente. Esta modalidad entrecruzada asegura como principal resultado dar cuenta de la posibilidad de una mutua comprensión cultural, no a partir del conjunto de códigos discursivos más poderosos, sino del esfuerzo de un inter-logos, que sugiere el ensamblaje de dos o más conjuntos de códigos discursivos en vistas a una convivencia común. Esto es lo que cabría denominar el auténtico diálogo intercultural.

\section{INTRODUCCIÓN}

Este artículo recoge una línea de investigación filosófica de estos últimos años, donde hemos situado la cuestión de la acción intercultural dentro de una discusión contemporánea acerca de los aportes y limitaciones de dos perspectivas filosóficas del discurso'. Se ha opuesto, a veces, de un modo exagerado, la hermenéutica entendida como «teoría crítica de las ideologías» (tal como lo elaboran por ejemplo, Habermas y Apel), y la hermenéutica entendida como «recolección del sentido» de una tradición histórico-cultural (como se la

\footnotetext{
' La detallada controversia entre HABERMAS y GADAMER en José María AGUIRRE, Raison critique ou raison hermenéutique?, Paris-Vitoria, Cerf-Eset, 1998.
} 
encuentra por ejemplo en obras de conocidos hermeneutas, tales como Gadamer, Ricoeur y Ladrière). Empero, una lectura cruzada de las principales categorías de ambas teorías del discurso, permite plantearse una gran interrogante frente a tal escisión, que podría formularse del modo siguiente: ¿es consistente separar, al interior de un análisis discursivo, las dimensiones propias de la articulación de un sentido histórico con las condiciones formales que permiten desplegarlo en el marco de una teoría de la acción comunicativa?².

Si consideramos al menos la propuesta filosófica representativa de cada perspectiva, tal como la encontramos en la obra de Habermas y Ricoeur, quedaría de cierta manera en evidencia que el recurso a las dinámicas propias del mundo de la vida es el punto de apoyo de una teoría de la discursividad que reúne lo histórico-cultural con lo universal. Por lo menos en Habermas aparece sustentando la posibilidad de vincular estos recursos del mundo de la vida con una teoría de la acción comunicativa y en Ricoeur se la propone como la base de una identidad narrativa; en ambos casos se sugiere un marco de algo así como una «razón reconstructiva», que ha sido elaborada en la obra de J. M. Ferry ${ }^{3}$.

Si consideramos los dos autores referidos, se podría indicar que la propuesta desarrollada particularmente por Habermas, en su lectura del Lebenswelt husserliano, no se refiere a una intuición central de un mundo circundante originario, sino que alude a aquellos elementos que destacan el carácter intersubjetivo del mismo entorno vital, por lo que se trataría en consecuencia de una reutilización de esta categoría fenomenológica para justificar una teoría intersubjetiva de la sociedad ${ }^{4}$.

Señalemos algunas breves indicaciones. En los años 1990, la categoría del mundo de la vida se vuelve central en la obra de Habermas para entender adecuadamente toda La teoría de la acción comunicativa ${ }^{5}$. Aquí enuncia su crítica central a la fenomenología de Husserl, en el sentido de que tal categoría se despliega aún en el marco de una filosofía de la conciencia, mientras que él pretende reconstruirla en diálogo con Schütz y Luckmann en el marco de una acción intersubjetiva, como «un acervo de patrones de interpretación transmitidos culturalmente y transmitidos lingüísticamente» ${ }^{6}$. En otro artículo bastante conocido, Habermas sintetiza su perspectiva como una toma explícita de posición: "voy a dejar de lado el método de Husserl y también el contexto en que introduce su concepto del mundo de la vida; pero hago mío el contenido mate-

\footnotetext{
2 MAESSCHALCK Marc, Normes et contextes. Les fondements d'une pragmatique contextuelle, Hildesheim - Zürich - New York, Georg Olms, 2001.

${ }^{3}$ FERRY Jean- Marc, L'Ethique reconstructive, Paris, 1996.

${ }^{4}$ Cf. SAN MARTIN Javier (Ed.), Sobre el concepto de mundo de la vida, Madrid, 1994, pp. 241 -

258 y PIZZI Jovino, El mundo de la vida. Husserl y Habermas, Santiago de Chile, 2005.

${ }^{5}$ Cf. HABERMAS Jürgen., Teoría de la acción comunicativa, y Pensamiento postmetafísico (traducción castellana de M. Jiménez Redondo, Madrid, 1987 y 1990).

${ }^{6}$ HABERMAS Jürgen, Teoría de la acción comunicativa, Madrid, 1987, tomo II, p. 176.
} 
rial de sus investigaciones suponiendo también que la acción comunicativa está inserta en un mundo de la vida que nos provee de la cobertura que es ese masivo consenso de fondo que se encarga de absorber riesgos de disentimiento $»^{7}$.

Por ambas referencias explícitas, parece claro que Habermas no tiene dificultades de empalmar su concepto de acción comunicativa con el de mundo de la vida, a pesar de las dificultades que se pueden detectar; ; empero es conveniente indicar que en este caso ya no estamos hablando en un sentido fenomenológico estricto, sino de las condiciones de una reconstrucción de los presupuestos de la racionalidad social; por lo tanto se refiere a la justificación de las ciencias sociales y humanas.

La relevancia de esta categoría del mundo de la vida en una teoría del discurso se la encuentra también en la hermenéutica del lenguaje por la que no se puede llegar a precisar la reconstrucción normativa si no es a partir de mundo que apela una cierta tradición cultural y mítica. Ricoeur ha destacado el vínculo en la tensión entre lo universal y lo histórico que ha descrito en muchos de sus textos: "Vivimos en un mundo que precede toda cuestión de la validez. Pero la cuestión de la validez precede todos nuestros esfuerzos para dar sentido a las situaciones en las que nos encontramos ${ }^{9}$. En otro texto relevante, donde se quiere articular la relación entre los presupuestos de la fenomenología y de la hermenéutica, dice Ricoeur explícitamente: «El retorno al Lebenswelt puede desempeñar mejor este papel paradigmático para la hermenéutica siempre que el Lebenswelt no se confunda con ninguna inmediatez inefable o se identifique con la envoltura vital y emocional de la experiencia humana, sino que designe esta reserva de sentido, este excedente de sentido de la experiencia viva, que hace posible la actitud objetivadora y explicativa ${ }^{10}$.

Aunque los textos citados se ubican en matrices y proyectos teóricos diferentes, nos parece que la cuestión del mundo de la vida aparece justamente como ese sentido histórico-cultural que precede todo posible acuerdo intersubjetivo y toda actitud que nos permita objetivar un conocimiento intercultural. Ésta es la base del diálogo intercultural que busca hacer más adecuado el vínculo entre contexto cultural y racionalidad humana.

En consecuencia nos parece que, a partir de esta categoría del mundo de la vida, se puede establecer teóricamente que este modo de pensar el entrecruzamiento entre la hermenéutica y la pragmática -como teorías relativas al sentido de prácticas comunicativas o que pueden ser descritas al modo de los tex-

\footnotetext{
${ }^{7}$ HABERMAS Jürgen, Pensamiento postmetafísico, Madrid, 1990, pp. 88-89.

${ }^{8}$ JIMÉNEZ REDONDO Manuel, Introducción, en HABERMAS Jürgen, Escritos sobre moralidad y eticidad, Madrid, 1991, p. 12-17.

${ }^{9}$ RICOEUR Paul, A l'École de la Phénoménologie, Paris, 1986, p. 295. Cf. LADRIÈRE Jean, «Le destin de la raison et les tâches de la philosophie», en Vie sociale et destinée, Namur, 1973, pp. 1937.

${ }^{10}$ RICOEUR Paul, Del Texto a la Acción, (Trad. castellana de Pablo Corona), México, 2002, segunda edición, p. 60.
} 
tos-, permite demostrar un nuevo modo de razón «dialogal y comunicativa». En este nuevo sentido, la razón en su dimensión teórico-práctica, siempre de acuerdo con este contexto filosófico del giro lingüístico, posibilita remontar hacia la estructuración interna del lenguaje mismo, que comporta una estructura objetiva -la lengua- y una estructuración subjetiva e intersubjetiva -el discurso-.

Este importante resultado que estructura el sentido al significado hace posible descubrir la génesis de las significaciones, tanto en el proceso de elaboración de los lenguajes de las ciencias como en los diversos niveles de significación de las formas discursivas culturales. A través de este vínculo podemos afirmar que la experiencia y la acción humanas tal como aparecen en los contextos culturales -que es lo que está en juego en lo intercultural-, permite redescubrir y justipreciar los dispositivos semánticos de los discursos culturales que habían sido descuidados o despreciados por el cientificismo o por las filosofías racionalistas. En los apartados siguientes daremos cuenta de las nociones que permiten estructurar esta propuesta del diálogo intercultural: la discursividad y el inter-logos, la reflexividad, el vínculo entre mythos-logos, y el modelo de la traducción.

\section{La discursividad y el inter-logos}

Se podría decir que la postura hermenéutica es fuerte en la comprensión de un sentido narrativo, unida a la afirmación de valores asociados al mundo de la vida; en este campo las tesis pragmáticas tienen varias dificultades, en especial para demostrar adecuadamente los procesos de aplicación de las normas a los contextos. Los valores aprendidos por los sujetos en los mundos de vida son parte de soportes simbólicos y narrativos con los que debe contar una argumentación que responda a las exigencias de los contextos, como dice Michelini: «Por ello, cuando discutimos en serio, es porque queremos resolver algún problema del mundo de la vida. No se trata, por lo tanto, de contraponer artificialmente la vida a la argumentación, el vivir al argüir...» ${ }^{11}$.

El modelo del diálogo intercultural, en tanto es parte de una pragmática discursiva, exige acoger la dimensión procedimental de la pragmática puesto que requerimos un proceso argumentativo y universal que contribuya a precisar las reglas concretas que se requieren para resolver los conflictos inherentes a la acción en sus contextos. Esto entrega la indicación pragmática elemental de que todo discurso intersubjetivo necesita el planteamiento de razones. Por lo tanto en el terreno de las relaciones humanas se exige un tratamiento razonado en que debemos ponderar e incorporar al máximo número de involucrados. Empero, esto requiere que las razones no se definan desde una visión deformada de la racionalidad hegemónica. Las razones de las que se trata aquí, no

${ }^{11}$ MICHELINI Dorando, Globalización, interculturalidad y exclusión. Ensayos ético-políticos, Río Cuarto, 2002, p. 122. 
son aquéllas inherentes a un sistema monocultural sino que son las que se conforman a partir de prácticas reflexivas asociadas a las diversas formas discursivas existentes en cada cultura: por ello cabe distinguir el auténtico diálogo del diálogo inauténtico.

La definición pragmática de las condiciones discursivas exigidas por un auténtico diálogo intercultural, Ileva a reconfigurar con más precisión en la idea que Gadamer ha formulado con la expresión de las razones de los otros ${ }^{12}$. Si nosotros y los otros tenemos razones de nuestros puntos de vista, entonces habría que defender la idea que todos tendrían la razón, y con ello caeríamos indefectiblemente en los errores del relativismo y del hermeneuticismo (sería ésta una tesis contextualista radical). El error de esta concepción es que cierra las posibilidades del intercambio de razones que exige el diálogo y la comunicación. Pero sostenemos que el extremo contrario no es tampoco plausible, a saber la tesis de un universalismo radical, a saber que podemos comunicar todo a todos. Nos parece que ambos extremos tienen defectos teóricos insuperables: el primero encierra las formas discursivas en el particularismo del ethos, y el segundo exagera el discurso argumentativo, presuponiendo el triunfo de la razón formalista sobre la razón experiencial ${ }^{13}$.

En este plano es menester sostener contra ambos extremos que la postura pragmática, instruida por la hermenéutica, exige una postura mediadora que justifica un principio o meta-norma universal que requiere ser ubicado frente a los discursos y prácticas de los sujetos en contexto. La pragmática en sentido estricto justifica las normas que aseguran un tratamiento equitativo a todos los hombres y mujeres de todas las culturas, requieren un levantamiento de criterios fundacionales de los contextos de acción. Los meta-contextuales se refieren a las prácticas de comprensión «entre-culturas», mientras que los intra-contextuales aluden a las prácticas de comprensión al interior de nuestro modo de vida. Ambos no pueden definir los procedimientos sino que establecen criterios reguladores comunes. Este carácter procedimental es preciso recuperarlo, pero no es consistente desgajarlo de los contextos de vida que son el horizonte donde se articulan las acciones de los sujetos. En nuestra óptica los procedimientos surgen a través del dinamismo operativo de los registros discursivos mismos, es en particular a partir de ellos, que se establece la dinámica del sentido abierto a la universalidad, por lo tanto los procedimientos deben ser articulados con las formas reflexivas operantes en cada cultura.

La modalidad pragmática precisa las condiciones lingüísticas que todos los interlocutores, que se quieren efectivamente entender, utilizan para obtener acuerdos que respeten las especificidades propias. Éste es el auténtico diálogo intercultural: "Sólo si el que pertenece a la cultura tenida como superior trasciende su cultura desde dentro relativizándola y no considerándola ya como

\footnotetext{
12 DOMINGO MORATALLA Agustín, El arte de poder no tener razón. La hermenéutica dialógica de H. G. Gadamer, Salamanca, 1989.

${ }^{13}$ CONILL Jesús, «Hermenéutica antropológica de la razón experiencial», en Discurso y Realidad, Madrid, 1994, pp. 131-143.
} 
parámetro, es posible entablar un diálogo intercultural realmente simétrico y simbiótico» ${ }^{14}$.

Enfatizando la conciliación entre estas dos propuestas (hermenéutica y pragmática), se requiere demostrar la necesidad de un nexo preciso por el que ambas se tornan complementarias. Si se logra demostrar esto, se podría avanzar consistentemente en una teoría de una razón ético-práctica que ayude a comprender y compartir las razones de los otros en un auténtico diálogo intercultural. Estas razones requieren modularse, al mismo tiempo, como parte de una actividad hermenéutica (en tanto considera la comprensión de las actividades expresivas y significativas de los mundos de vida, en particular por su esfuerzo de contextualización de los símbolos, textos, discursos, narraciones presentes en los diversos sujetos y comunidades) y de una actividad pragmática (en tanto destaca la necesaria validación de un tipo de lenguaje que asegure enunciados válidos, que puedan ser confrontados y que entregue resultados fiables no sólo para una comunidad de vida).

El diálogo intercultural que implica la aceptación de la categoría de las razones de los otros supone aceptar entonces, que la reflexividad humana no es algo exterior a los procesos productivos de los contextos, sino que ella se vuelve operante internamente a través de la articulación de las formas discursivas, y exige aceptar acuerdos básicos sobre las reglas y procedimientos. Este vínculo entre reflexividad contextual y procesos de mediación normativos no puede ser puramente localizado de acuerdo a los usos específicos de cada cultura, pues ello no aseguraría el entendimiento de unos con otros, y en forma especial entre aquéllos que no comparten los mismos mundos de vida.

Una idea como la referida requiere necesariamente una crítica del contextualismo en su versión más radical, que se niega a la apertura a las formas discursivas de los otros; como si la interconexión alterativa fuera siempre una mera imposición definida por las culturas más poderosas. Ya hemos indicado que junto a este contextualismo radical, sería preciso cuestionar seriamente una determinada forma de entender la inconmensurabilidad de las culturas, lo que implicaría aceptar, al menos hipotéticamente, la posibilidad de llegar a definir formas procedimentales que sean compartidas por sujetos que mantienen raigambres distintas a los contextos valorativos y normativos. En este sentido, se exige que la propia teoría de los actos de habla, que ha dado origen a la discusión acerca de la heterogeneidad de los discursos, retome la cuestión central del lenguaje que se privilegia para enunciar tal heterogeneidad. Si es correcto afirmar que existen reglas apropiadas de los juegos del lenguaje, como lo indica el segundo Wittgenstein, no lo es afirmar que entre ellas no exista ninguna posibilidad de convergencias que permitan pasar de una a otra, que al menos permita reconocer las reglas que le son necesarias para hacer significativo un discurso. Aquí resultará relevante el tema de la traducción que

${ }^{14}$ TRIGO Pedro, «Establecer una sociedad multiétnica y pluricultural en un estado de justicia. El diálogo intercultural en Venezuela», en Revista ITER 28, (2002), p. 74. 
vamos a exponer sucintamente más adelante, como un modelo del diálogo intercultural.

Por diálogo intercultural entenderemos aquél que no se precipita rápidamente a una conciliación apresurada para anular las diferencias entre los registros discursivos (sostener que existen las mismas reglas universales para todos los discursos), ni tampoco el tipo de diálogo que se cierra a reconocer las dificultades efectivas existentes en la comunicación entre seres humanos que han conformado diferentemente sus mundos de vida (sostener que las reglas de los registros discursivos son todas diferentes). Este diálogo plantea una modalidad, más paciente, para entender a los otros desde las propias articulaciones discursivas, lo que implica sostener que en el ejercicio para alcanzar las razones de los otros existe siempre una mediación de la articulación de los registros en que se conforman los sujetos. Es un diálogo intercultural aquél que colabora en el difícil arte de comprender los propios procesos discursivos que no se pueden hacer nunca de un modo claro sin el apoyo de los otros ${ }^{15}$.

El ideal moral de con-vivir con otros, en el respeto de las distintas manera de vivir y que asegure una vida moral plural, exige este re-conocimiento de las reglas discursivas. Este esfuerzo teórico exige definir la dinamicidad de los procesos discursivos que forjan los recíprocos reconocimientos. Se trata, entonces, de un diálogo universal y contextual, que asume las dificultades históricas de la convivencia humana cargadas de a-simetrías y de discriminación. Por ello, lo que cabe entender por razón discursiva en este modelo del diálogo intercultural hay que comprenderla en el sentido de la hermenéutica crítica antes referida, es decir, de un proceso de constitución del sentido de una vida y de un conjunto de prácticas significativas tanto para el propio mundo de vida, como eventualmente para los otros.

Empero, esta tesis no va de suyo, ya que es preciso distinguir entre el comprender a otro dentro de mi mundo de vida y que comparte rasgos relevantes de mi misma matriz discursiva cultural y la comprensión de otro que forma parte de una cultura totalmente diferente. Pensamos que en ambos casos, con diferencias notorias por cierto, se está obligado a aceptar una cierta tensión entre unidad-diversidad de la modalidad intersubjetiva, que justamente pueden resolverse si apelamos al concurso de una discursividad propia del diálogo intercultural.

Por esto, la cuestión ya debatida de las razones de los otros no puede ser radicalizada a partir de un modelo de su diferencia ni subsumida bajo un mismo logos universal ya predefinido por la propia tradición occidental. Esto supondría, como lo ha indicado acertadamente Dina Picotti, «reconocer explícitamente la construcción histórica del logos humano como inter-logos» ${ }^{16}$, es decir, la posibilidad de entender a los otros en sus razones a partir de una poli-

\footnotetext{
${ }^{15}$ CORTINA Adela, Ciudadanos del mundo: Una teoría de la ciudadanía, Madrid, 1999.

${ }^{16}$ PICOTTI Dina, «Sobre "Filosofía Intercultural"» en Stromata 52, (1996) p. 298.
} 
fonía de logos, por el que somos conscientes de la modalidad de mi logos cultural y de cómo podemos abrirnos a otros logos.

Esta afirmación exige cuestionar la comprensión occidentalizante de esta afirmación, en clave de crítica de una razón monocultural. Esto podría aclararse con un par de observaciones, desde el punto de vista intercultural, sugeridas por Panikkar. Para él el problema epistemológico de la comprensión del otro es relevante, puesto que: «La novedad y la dificultad de la filosofía intercultural consiste en que no existe una plataforma metacultural desde la que realizar una interpretación de las culturas, debido a que toda interpretación es nuestra interpretación. Es verdad que este intento para interpretar otra cultura es un paso intermedio que nos abre a influencias externas y nos ofrece un cierto conocimiento del otro. Pero el 'otro' no se sabe a sí mismo como 'otro'. El 'otro' para la otra cultura es 'nosotros'. Nos encontramos delante de una aporía: ¿cómo preservamos nuestra racionalidad al trascenderla?, ¿cómo podemos entender al 'otro' si no somos el otro?» ${ }^{17}$.

Fornet-Betancourt plantea también otras consideraciones hermenéuticas acerca de la dificultad de la comprensión del otro, y las vincula con el predominio de un tipo de racionalidad monocultural, que no es consciente de todas sus mediaciones contextuales en la comunicación comprensiva del otro: «Nuestra teoría del entender tendría que hacerse cargo del otro; precisamente por ser sujeto histórico de vida y de pensamiento, no es nunca constituible ni reconstruible desde la posición de otro sujeto. Frente al otro no cabe entonces la reconstrucción teórica desde mi forma de pensar, sino la reserva teórica del que se pone a escuchar el discurso de otra forma de pensar, y ya vislumbra en esa escucha el comienzo de la trans-formación recíproca. La tarea consistiría entonces en emprender la reformulación de nuestros medios de conocimiento desde el pleito de las voces de la razón o de las culturas en el marco de la comunicación abierta, y por la reconstrucción de teorías monoculturalmente constituidas" ${ }^{\prime 18}$.

Estas observaciones plantean como problema central la cuestión de la ecuación entre racionalidad y lenguaje, que nos parece que está en el centro de este debate levantado por la ética de la discusión de Apel y Habermas, pero que está contenido asimismo en el problema del sentido, desarrollado en la hermenéutica de Gadamer, Ricoeur y Ladrière. Nos parece que el diálogo intercultural gana al situarlo en el terreno de una crítica pragmática y hermenéutica de la razón monocultural. Habría que concluir que, tal como la ha practicado una filosofía occidental, hemos elaborado una construcción frecuentemente hegemónica, que no acepta «las razones» de aquellos que no han alcanzado el nivel de racionalismo de nuestra cultura. Este racionalismo que proviene de la antigüedad griega, se ha desarrollado en una parte importante de

\footnotetext{
17 PANIKKAR Raimundo, en ARNAIZ G., El discurso intercultural. Prolegómenos a una filosofía intercultural, Madrid, 2002, p. 47.

${ }^{18}$ FORNET-BETANCOURT Raúl, Transformación Intercultural de la Filosofía, Bilbao, 2001, p. 42.
} 
la cultura occidental. Algunos pensadores actuales piensan que este racionalismo está graficado hoy en la ampliación del proyecto de la racionalidad científico-técnica a todos los mundos de vida. Ésta es la aportación de la ética discursiva (Diskursethik) que señala la necesaria disputa entre ciencia y técnica, y sus respectivas mediaciones normativas y valorativas.

Una crítica de las dimensiones etnocentristas que han predominado en las ciencias de las culturas y en el racionalismo occidental parece que es compartida por los filósofos de la pragmática y de la hermenéutica. Sin embargo, un enfoque intercultural agregaría una cuestión más, al asociar la crítica a la racionalidad imperante como un ejercicio de des-fundación de la racionalidad, no en contra de la racionalidad, sino del proyecto hegemónico asociado a la modernidad occidental. Por ello se busca demostrar que existen formas de saber que no han sido valoradas suficientemente en este marco racionalista. Por ello, consideramos que es preciso introducir la categoría central de la reflexividad.

\section{La categoría de la reflexividad}

Sostenemos que la filosofía intercultural exige el levantamiento de la categoría de la reflexividad. Se ha valorizado frecuentemente en las ciencias sociales el carácter reflexivo de los sujetos sociales en un entorno moderno, y contrapuesto a la tradición ${ }^{19}$. A veces, se la ha entendido como un ejercicio también moderno de una autenticidad reflexiva por A. Ferrara. Sin embargo, queremos aquí, sin desconocer ambos aportes, ponerla más bien en los términos de una categoría histórico-cultural por la cual queremos dinamizarla como proceso de la humanidad, y queremos subrayar la idea de que la reflexividad se refiere a un proceso inherente a las culturas humanas, no necesariamente modernas, desafiadas al diálogo y a la comunicación con otras culturas. La idea de la reflexividad es clave, por tanto, para consolidar una instancia crítica dentro de las exigencias del diálogo intercultural, ya que permite desvelar las formas ideológicas de la racionalidad como astucia del poder. Ella contribuye a avanzar en la adecuada crítica de la razón abstracta homogeneizante, a partir del reconocimiento de los otros saberes culturales. Esta es la razón práctica intercultural que responde a los saberes de los mundos de vida que no han sido colonizados, para usar el vocabulario habermasiano.

No oculta esta razón su enraízamiento en la memoria de las luchas pasadas, de las resistencias y de los diversos sufrimientos vividos por los seres humanos. Las deudas frente a los antepasados -que nos han entregado los espacios de convivencia-, las tradiciones de resistencias, la espera y el dolor humano nos acercan a los hombres de todas las culturas. Las tradiciones no sólo son afirmaciones legadas de un mundo pacífico, sino de las deudas que tenemos frente a los que nos han legado nuestra eticidad de lucha y de resolución de los

${ }^{19}$ GUIDDENS Anthony, Consecuencias de la modernidad, Madrid, 1993, p. 44ss. 
conflictos. En este sentido, la reflexividad apunta a destacar las diversas formas culturales que definen los saberes culturales de los pueblos.

Sin embargo, es correcto decir que el con-vivir conflictivo con los otros diferentes de mi mundo de vida no supone de ningún modo sostener la oposición radical entre "las razones» derivadas de los registros discursivos de mi mundo de vida y «las razones» relativas a los otros discursos de otros mundos de vida. Sostener una oposición radical implicaría introducir una ruptura irremediable en el terreno de la reflexividad moral y por lo tanto la imposibilidad del diálogo intersubjetivo en el ámbito de la acción. Uno de los presupuestos comprensivos de una filosofía intercultural es que toda acción de un ser humano conlleva significados «razonables» que pueden ser rastreados desde el interior de los significados y sentidos que otorgan los mundos de vida, y que están abiertos, de un cierto modo, a otros mundos de vida.

Se ha hecho notar que, cuando los etnólogos o los antropólogos o los que escriben sobre «los otros» descalifican conductas o valores específicos de otra cultura, frecuentemente sostienen en sus afirmaciones presupuestos que son producto de un velo de a-criticidad y de ignorancia acerca de las conductas y valores inapropiados de su propia cultura, cuando no son claramente la expresión de una forma de legitimación de la cultura del colonizador. Sin embargo, este tipo de argumentación no surge sólo desde la crítica actual a los precursores de los estudios culturales, sino que ha sido característica de la reflexividad existente en todas las culturas indígenas o dominadas frente a las culturas colonizadores o dominantes. En este plano habría que explicitar que no es sólo inaceptable la descalificación de las «razones de los otros», sino que es inconsistente con una mirada mutua desde la criticidad. Se requiere sostener la posibilidad de que las razones de los «otros» $y$ «las razones» que emergen de mi mundo de vida se articulen llegando a acuerdos, que tendrán que ser definidos por el mismo proceso de intercomprensión.

Por ello estamos de acuerdo con las categorías propuestas por los filósofos latinoamericanos que destacan el carácter de interpelación, por la que se reconoce esta participación de los otros en el diálogo, frecuentemente asimétrico: el grito del otro es siempre una forma de interpelación que cuestiona el sistema y desvela la a-simetría estructural. "Estos 'Otros', sin embargo, no son los otros 'que la razón', sino que son otros que tienen sus 'razones' para 'proponer', 'interpelar' contra la exclusión y en favor de su inclusión en la comunidad de justicia ${ }^{20}$, o como dice Fornet-Betancourt: «El encuentro con el otro es así interpelación; interpelación desde la que debería ser repensada nuestra manera de pensar; pues en esa situación experimentamos que hay otro horizonte de comprensión que nosotros no fundamos y que, por eso mismo, nos desafía como una posibilidad de respectivizar nuestra propia situación original $»^{21}$.

${ }^{20}$ DUSSEL Enrique, Debate en torno a la ética del discurso de Apel, México, 1994, p. 88.

${ }^{21}$ FORNET-BETANCOURT Raúl, Transformación Intercultural de la Filosofía, 2001, p. 41. 
Sin embargo, en este punto es preciso establecer una breve conexión con el tema de la inconmensurabilidad ${ }^{22}$. Desde nuestra perspectiva intercultural es menester tener un concepto más preciso de inconmensurabilidad. Nos parece que el que propone Berstein es adecuado porque evita resolver la cuestión jugando entre dos extremos ya cuestionados. Esta problemática se relaciona con dos posiciones discutibles acerca del diálogo intercultural, a saber: por una parte, el relativismo radical que tiende a cerrar el diálogo, en la medida en que pretende denunciar la racionalidad dominante que asfixia los componentes reflexivos del mundo de vida, por lo cual la inconmensurabilidad permitiría sostener la permanente resistencia a las culturas hegemónicas e invasoras; por otra parte, el universalismo radical integra el conjunto de las racionalidades en nombre del logos entendido como razón universal que sería la medida de todas las racionalidades inherentes a las culturas humanas. Desde este enfoque, las culturas se pueden mensurar a partir de un parámetro que se levanta como el único válido para todos, pero que termina reduciendo el papel de lo histórico y de lo particular.

Parece impropio que desde estas dos perspectivas, particularista y universalista, se puedan caracterizar adecuadamente las formas razonables de la acción humana llamada a realizarse contextualmente en el encuentro intersubjetivo. Parece necesario repensar la racionalidad práctica no como una unidad discursiva compacta, sino como conjuntos discursivos pluriformes y dinámicos, que se ajustan a los logros obtenidos por las teorías del sentido y significado de la hermenéutica y de la pragmática. Esto se podría esquematizar en una discusión que ha sido clásica en nuestros estudios de filosofía y teología, pero que aquí quisiera interpretarla en el marco de una reinterpretación de la noción del mito y del logos en el marco de este modelo del diálogo intercultural.

\section{Un nuevo esbozo de la distinción entre mythos y logos}

Una aportación sugerente en este sentido la encontramos en la obra de Pannikar. Él sostiene que la contraposición griega clásica entre logos y mythos ha conducido al concepto occidental de la razón a través de una perversión racionalista, que le ha impedido ubicar la centralidad de lo narrativo en el seno de la cultura, en vez de ayudar a reconocer sus diversas voces, su polifonía ${ }^{23}$. La respuesta que ofrece Panikkar cuestiona ciertamente la primacía de una determinada forma predominante en Occidente, en que se ha homologado la razón a logos, pero olvidando que ella también es mythos. Al respecto nos señala: «El lenguaje no es solo logos; es también mythos y si los logoi pueden de algún modo ser traducidos, los mythoi son muchos más difíciles de transplantar. La 'comprensión' humana en el sentido de armonía y concordia

\footnotetext{
${ }^{22}$ Este tema que hizo famoso Thomas KUHN en su discusión acerca de los paradigmas científicos, ha sido puesto de nuevo en boga en el terreno pragmático y ético-político por el filósofo norteamericano Richard, RORTY.

${ }^{23}$ FORNET-BETANCOURT Raúl, Transformación Intercultural de la Filosofía, 2001
} 
requiere la comunión con el mythos y no se soluciona con el sueño de la lingua universalis de la 'Ilustración' en donde toda palabra tiene un sentido preciso $»^{24}$. Desde nuestra óptica se requiere enfatizar entonces matrices en que reconozcamos los diversos logos, pero mostrando aquellos aspectos limitantes para el encuentro con los otros. Ahora bien, sabemos que el mythos no puede ser entendido sólo como experiencia sino que es también un discurso. Esto es particularmente verdadero en el ámbito de lo que se podría denominar la razonabilidad o la reflexividad que es una de las categorías claves de nuestro punto de vista intercultural, puesto que ella surge desde los niveles simbólicos y narrativos más básicos de una cultura humana.

Desde el momento en que afirmamos el reconocimiento de la problemática de las razones de los otros, destacamos otras formas discursivas diferentes a la argumentación, que no se puede considerar más la forma por excelencia para debatir en el terreno comunicativo. Nos parece que en el sentido estricto de una teoría de las formas discursivas -que se vincula con los actos de hablahabría que reconocer que la idea medular es asociar la reflexividad con las diversas formas discursivas; ellas son las herramientas en las que se apoya cualquier sujeto de una cultura específica para expresar los significados y sentidos de sus discursos humanos. Esta idea es preciosa para el análisis de la acción ético-cultural.

Es preciso reconocer que existen en todas las culturas diversos niveles reflexivos, por lo que entender por ejemplo un determinado enunciado ético exige insertarlo en un contexto significativo preciso. Es justamente el terreno moral y ético aquél en el que no se puede dejar única y exclusivamente en las manos de los especialistas la clarificación de los sentidos morales, es una capacidad posible de ser desarrollada por todos y cada uno de los sujetos a fin de alcanzar su plena vida moral. El verdadero fin de la vida ética es lograr dar cuenta de las acciones de uno mismo y de la apertura a otros sujetos que comparten nuestro mundo de vida.

Si esta tesis es correcta, podemos afirmar que en todos los contextos culturales se requiere alcanzar niveles de enjuiciamiento frente a determinadas situaciones inhumanas. En cada cultura la vida ética se logra a través de las virtualidades de las formas discursivas y éstas pueden ser llevadas a su nivel de mayor reflexividad. El trabajo de los especialistas coincidiría entonces con la posibilidad de sostener que el problema de la lingüisticidad contextual permite comprender las relaciones intersubjetivas, lo que implica poner de relieve conjuntamente la perspectiva pragmática y la hermenéutica en el análisis de las razones. Se lograría establecer así una concordancia entre las razones de los otros y las diversas formas discursivas que expresan la polifacética experiencia humana y moral. Existiría entonces la posibilidad de sostener que la relación práctica, por una parte, no se reduce de ningún modo a un acto comu-

\footnotetext{
${ }^{24}$ PANIKKAR en ARNAIZ G., El discurso intercultural. Prolegómenos a una filosofía intercultural, 2002, 50 .
} 
nicativo-lingüístico ${ }^{25}$, pero por otra parte se lograría aprovechar el tema de las «razones morales» de un modo eminentemente comunicativo y reflexivo, en el terreno de los actos de habla.

Esta cuestión de una discursividad horizontal o vertical es preciso complejizarla pues las relaciones intersubjetivas se dan en planos diferentes en el ámbito del discurso moral en nuestras culturas. Es correcto afirmar que existe una determinada verticalidad como la que exige el aprendizaje entre maestro y discípulo, entre padres e hijos, pero es necesario lograr siempre en algún momento, si propendemos a una personalidad moral autónoma, que logremos una cierta simetría discursiva como la que se exige en el diálogo entre pares. Diciendo esto queremos sostener que existe una tensión entre horizontalidad y verticalidad que nos es vital para comprender la compleja articulación discursiva existente en las culturas, por lo cual esta tesis exigiría un nuevo reconocimiento de otros modos de vida que han constituido la constitución del sentido entre nosotros. Por ello no hay ética intercultural sin mediación intersubjetiva ${ }^{26}$. Entre horizontalidad y verticalidad discursiva existe una serie de graduaciones contextuales que deberíamos reconocer como ejercicios de resistencia ya articulados en la interacción de las culturas dominantes y de las culturas dominadas. En este punto, es preciso indicar que una cierta hegemonización occidentalizante ha conducido a privilegiar la verticalidad sobre la horizontalidad.

Pero el punto nuclear, volvemos a reiterar, es saber si el fracaso de una relación de comprensión intersubjetiva es la última palabra, o existe la posibilidad de agudizar otras formas de búsqueda de un entendimiento alterativo que no es fácil, pero que requiere de una actitud que es plenamente ética. Nos dice Berstein: "Pero la respuesta a la amenaza de este fracaso práctico -que a veces puede ser trágico- debe ser ética, esto es: asumir la responsabilidad de escuchar con atención, usar nuestra imaginación lingüística, emocional y cognitiva para captar lo que es expresado y dicho en tradiciones 'extrañas'. Debemos hacer esto de manera que resistamos a la doble tentación, tanto de asimilar superficialmente lo que otros dicen en nuestras propias categorías y lenguaje sin hacer justicia a lo que es genuinamente diferente y puede ser inconmensurable, como de despachar lo que el 'otro' está diciendo como si fuera un disparate incoherente. También debemos resistirnos al doble peligro de la colonización imperialista y del exotismo inauténtico -que a veces es denominado 'vivir como los indígenas' $»^{27}$.

Dicho esto, se puede inferir que el diálogo intercultural está lejos de reformular la tesis de la plena comprensión ideal de la ética discursiva (horizontalidad) ni tampoco la aceptación de la incomprensión histórica discursiva de los

\footnotetext{
${ }^{25}$ DUSSEL Enrique, Debate en torno a la ética del discurso de Apel, 1994, p. 83.

${ }^{26}$ Cf. SALAS Ricardo, Ética Intercultural. Ensayos de una ética discursiva para contextos culturales conflictivos. (Re)Lecturas del pensamiento latinoamericano, Santiago de Chile, 2003.

${ }^{27}$ BERSTEIN Richard, "Una revisión de las conexiones entre inconmensurabilidad y otredad» en Isegoría 3, (1991) pp. 13-14.
} 
contextos culturales (verticalidad). Es necesario forjar un modelo teórico que permita establecer efectivamente su articulación mutua. Ello puede encontrarse en el modelo de la traducción según la indicación de Ricoeur, y que constituye un verdadero problema filosófico ${ }^{28}$.

\section{El modelo de la traducción}

Hagamos referencia sucintamente al modelo de la traducción, porque permite justamente ilustrar la necesidad de acordar las reglas específicas necesarias para construir espacios comunes de intercomprensión y que den cuenta de dos códigos lingüísticos y culturales que articulen una fusión de horizontes significativa, que logre comprender los sentidos y significados en la forma más recíproca posible ${ }^{29}$. En este sentido, el tema de la traducción se vuelve el intermediario de la comprensión del lenguaje del otro a partir de las posibilidades que abre mi propio lenguaje y el lenguaje del otro, reconociendo que existen ciertas condiciones que preparan el trabajo de distancia y de pertenencia, y que asimismo tiene sus riesgos y limitaciones: "El punto de partida efectivo para el diálogo intercultural en nuestra situación actual consistiría en diálogos entre traductores. Esto es lo que quiere decirse cuando se recomienda que los interlocutores vayan al diálogo preparados. No basta con conocer la propia tradición; se debe también conocer, aunque sólo sea de un modo imperfecto, la cultura del otro. Es más, no podemos entender un texto a menos que conozcamos su contexto» ${ }^{30}$. En el mismo sentido, Ricoeur nos plantea: «En realidad el nombre de traducción alude a un fenómeno universal que consiste en decir el mismo mensaje de una manera distinta. Por la traducción, el locutor de un idioma se traspasa al universo lingüístico de un idioma extranjero. A cambio, acoge dentro de un espacio lingüístico la palabra del otro. Este fenómeno de hospitalidad idiomática puede servir de modelo a toda comprensión en la que la ausencia de lo que podría llamarse un tercero en sobrevuelo, pone en juego los mismos operadores de traspaso en...y de acogida en... cuyo acto de traducción es el modelo» ${ }^{31}$.

Esta referencia al modelo de la traducción es significativa para cerrar, por ahora, las tres problemáticas señaladas: la del diálogo intercultural en contextos a-simétricos, la de la inconmensurabilidad del otro y la posible derivación de reglas en contextos específicos de a-simetría, ya que permiten sostener una idea fuerte de la relación de traducción entre los mundos de vida, superando las posiciones de la comprensión total y la de la incomprensión total. Una filosofía intercultural, tal como ya ha sido definida, se abre a un espacio de recons-

\footnotetext{
${ }^{28}$ JERVOLINO Doménico, "La traduzione come problema filosofico», en Studium, 1 (2005), p. 60.

${ }_{29}$ SALAS Ricardo, "Conquista, traducción y lenguaje misionero en el siglo XVI», en Revista Mapocho 32, (1992) p. 213.

30 PANIKKAR Raimundo, en ARNAIZ G., El discurso intercultural. Prolegómenos a una filosofía intercultural, 2002, p. 45.

${ }^{31}$ RICOEUR Paul, Le Juste 2, Paris, 2001, p. 282.
} 
trucción discursiva de los criterios reguladores al interior de las culturas. Pero lo más decisivo es la posibilidad teórica de hacer un camino discursivo «interculturas» que contribuya a la elucidación de la comprensión de sí y a la comprensión del otro, definiendo los procedimientos que se necesitan para asegurar la mutua comprensión desde los contextos discursivos donde brota la productividad del sentido.

Antes de terminar este tema señalemos que el concepto más complejo de la inconmensurabilidad, que nos permite efectivamente llegar a fundamentar la posibilidad de la intercomprensión discursiva entre los diversos mundos de vida es crucial, porque un diálogo intercultural requiere dar cuenta siempre de una distancia cultural, junto a un proceso ininterrumpido de traducción, por el cual se hace posible involucrarse en un cierto nivel de pertenencia cultural. Lo que importa mostrar es que este mismo proceso requiere ser comprendido como una ética de la discursividad, y a la vez como una comprensión de nuevas condiciones para lograr una comunicación que trascienda las limitaciones de cada mundo de vida.

Una filosofía intercultural, tal como ya ha sido definida, se abre a un espacio de reconstrucción discursiva de las reglas dentro de las tradiciones narrativas y pragmáticas de las culturas. Por eso afirmamos la posibilidad teórica de fundamentar principios discursivos que permitan definir los procedimientos formales para establecer criterios mínimos que asegurarían, al menos, la mutua comprensión intercultural no asimétrica y la posibilidad de una resolución de los conflictos que atienda a los intereses de los interlocutores beligerantes.

Si recapitulamos los aspectos ganados en este terreno del diálogo intercultural, se podría afirmar que esta discusión entre una hermenéutica y una pragmática del discurso es teóricamente relevante porque permite elaborar un marco teórico que supera ciertas dicotomías heredadas de la filosofía racionalista e historicista. Este marco considera entonces desde una perspectiva más adecuada el vínculo entre contexto cultural y acción humana, ya que permite elaborar un análisis discursivo para contextos culturales conflictivos que necesita considerar al mismo tiempo el recurso a la narración y a la argumentación. La elaboración de esta propuesta discursiva es lo que denominamos ética intercultural. Tal como aparece definida en nuestro libro, ella puede ser entendida como: "Aquella forma de tematización discursiva del ethos al interior de una cultura, a partir del despliegue de los diversos niveles de reflexividad que se alcanzan en sus formas discursivas, y los posibles espacios de apertura comunicativa que se abren frente a otras formas de reflexividad asociadas a otros contextos culturales» ${ }^{32}$.

Esta definición de ética es deudora de un enfoque que considera el lenguaje en que se vierte la experiencia moral y los diversos sistemas de significación y sentido que tienen los enunciados morales en una cultura específica: pre-

\footnotetext{
${ }^{32}$ SALAS Ricardo, Ética Intercultural, 2003, p. 84. Otra concepción convergente se puede consultar en BILBENY Ética Intercultural. La razón práctica frente a los retos de la diversidad cultural, Barcelona, 2004
} 
ceptos, consejos, relatos, reglas y prohibiciones, etc. Esto tiene que ver con el concepto hermenéutico y pragmático ya esbozado, que considera los valores y normas como estructuraciones a partir del lenguaje, donde encontramos reglas lógicas, semánticas y pragmáticas básicas. Esto supone que dentro del discurso moral de una cultura siempre encontraremos un vínculo entre los valores propios y las exigencias universales, encontraremos por lo tanto en un ethos particular referencias a lo valórico y a lo normativo como partes inherentes de su complejo discursivo de eticidad y moralidad. Ambos no pueden separarse. Desde una perspectiva teórico-práctica de la interculturalidad no se puede desvincular lo deóntico (normativo) y lo axiológico (valores), ya que ambos constituyen el fenómeno de la moralidad y su reflexividad en un contexto cultural específico. Por ello el análisis racional que proporciona la filosofía es insustituible para analizar el fenómeno de la discursividad moral.

Existen de este modo cuatro problemas relevantes acerca del vínculo del discurso, del contexto y de la acción que cabría problematizar desde esta perspectiva del diálogo intercultural.

1. El análisis de los diversos discursos morales muestra el conflicto como un elemento fundamental de la deliberación humana y es por lo tanto el concepto clave para la comprensión de la acción humana en sociedades específicas, frecuentemente asimétricas.

2. El diálogo intercultural es decisivo para enfrentar contextos conflictivos, pero entendido siempre en plural frente a contextos heterogéneos y asumiendo formas dispares y plasmándose en niveles discursivos diversos.

3. La reflexividad propia de la acción humana en un marco intercultural se relaciona con los registros discursivos, si queremos comprender y enfrentar todos los conflictos internos de la propia cultura en transición como los eventuales conflictos externos frente a otras culturas en contacto; es esta reflexividad discursiva la que posibilita la convivencia con los otros.

4. La ética intercultural, como búsqueda de este espacio de comprensión entre-culturas, supone una opción por la discursividad, que valida un procedimiento definitorio de las reglas a partir de una modalidad contextual que valide el diálogo y hace inaceptable el recurso a la violencia y a la guerra.

\section{EPÍLOGO}

La filosofía intercultural en conclusión puede apoyarse firmemente en este cruce teórico para ensamblar la reconstrucción de las formas del discurso desde sus raigambres histórico-narrativas hasta sus formas de reconstrucción comunicativa más compleja- a partir de una concepción de la dinamicidad de la significatividad. En este marco más complejo podremos reconocer que, así como la forma lingüística habita en la dinamicidad del lenguaje nunca clausurado, la acción humana, como expresión del acto de una existencia, puede asegurarse su propia identidad ética a partir de una reapropiación reconstruc- 
tiva de sí mismo. En esta perspectiva dinámica la categoría central es la del «mundo de la vida». Desde este entorno vital específico brotan las experiencias originarias sobre las que se establecen los dispositivos de sentido. La acción humana está, por tanto, al mismo tiempo inserta en un mundo simbólico humano que sólo accede parcialmente a la apropiación de este esfuerzo por existir, y por consiguiente, debe recurrir a la universalización de sus contenidos éticos. Siguiendo la lectura entrecruzada de ambas teorías filosóficas hemos sido conducidos a otra parte, a destacar la relevancia de los rasgos de la racionalidad práctica y de los lenguajes morales.

La categoría del mundo de la vida, levantada por Husserl en su crítica a los tipos de epistemologías reduccionistas del siglo XIX, hoy es retomada por los filósofos de la hermenéutica y pragmática, para ser el ariete de la crítica a la racionalidad objetivadora y dominante iniciada por el positivismo, el naturalismo, el psicologismo y el historicismo predominantes en el siglo XIX. La cuestión filosófica más abstracta del diálogo intercultural, que hemos planteado aquí, es cómo esta noción del mundo de la vida levanta una crítica sistemática a las bases de la cientificidad moderna y al tipo de filosofía racionalista presente en la reducción matemática y empírico-formal de las ciencias, siguiendo lo ya indicado por Husserl en la Crisis, que son las bases del modelo tecnocientífico predominante.

Asimismo, el reconocimiento del mundo de la vida que es previo no es sólo una cuestión epistémica, sino eminentemente ética y política porque lleva a revalorizar el sentido del mundo individual y cultural, y a la posibilidad de abrirse a la comprensión de otros mundos individuales y culturales. Es relevante mostrar cómo una noción fuerte de diálogo intercultural, inspirada en esta categoría, es cuestionadora de los procesos tecno-científicos de homogeneización que provienen de un «pensamiento único» asociado a la globalización vigente.

Para concluir, señalemos que los problemas y perspectivas de la filosofía como diálogo intercultural refiere a una correcta crítica de este modelo monocultural que ha predominado en Occidente. Esta tesis central, desarrollada en este trabajo, permite visualizar de modo claro el relieve que asume el vínculo entre la hermenéutica y la pragmática del discurso, ya que ambas permiten dar cuenta de la mutua acción intercultural entre sujetos y culturas que exige que la filosofía actual asuma un papel relevante en la comprensión de los otros «extraños»y «extranjeros», asegurando las condiciones mínimas y procedimientos básicos sobre los que se levanta un verdadero diálogo intercultural. Pero, sobre todo la filosofía que asume este desafío, asegura la posibilidad de una verdadera intercomprensión mutua, no a partir del conjunto de códigos discursivos más poderosos, sino del esfuerzo de un inter-logos que sugiere el ensamblaje de dos o más conjuntos de códigos discursivos. Esto es lo que cabría denominar el auténtico diálogo intercultural que es parte de la vocación actual de la filosofía. 


\section{BIBLIOGRAFÍA}

AGUIRRE José María, Raison critique ou raison hermenéutique?, ParisVitoria, Éd du Cerf-Editorial ESET, 1998.

BERSTEIN Richard, "Una revisión de las conexiones entre inconmensurabilidad y otredad» en Isegoría 3, (1991) 5-25.

BILBENY Norbert, Ética Intercultural. La razón práctica frente a los retos de la diversidad cultural, Barcelona, Ariel, 2004.

CONILL Jesús, «Hermenéutica antropológica de la razón experiencial», en Discurso y Realidad, Madrid. Ed. Trotta, 1994, pp. 131-143.

CORTINA Adela, Ciudadanos del mundo: Una teoría de la ciudadanía. Madrid, Alianza, 1999.

DOMINGO Agustín, El arte de poder no tener razón. La hermenéutica dialógica de H.G. Gadamer, Salamanca, Publicaciones de la Universidad de Salamanca, 1989.

DUSSEL Enrique, Debate en torno a la ética del discurso de Apel, México, Siglo XXI, 1994.

FERRY Jean-Marc, L'Ethique reconstructive, Paris, Cerf, 1996.

FORNET-BETANCOURT Raúl, Crítica Intercultural de la Filosofía, Madrid, Trotta, 2004.

--- Transformación Intercultural de la Filosofía, Bilbao, Descléé de Brouwer, 2001.

GARCÍA GÓMEZ-HERAS José María, Ética y Hermenéutica. Ensayo sobre la construcción moral del "mundo de la vida» cotidiana, Madrid, Biblioteca Nueva, 2000.

GONZÁlEZ ARNAIZ Graciano (Ed.), El Discurso Intercultural. Prolegómenos a una filosofía intercultural, Madrid, Biblioteca Nueva, 2002.

GUIDDENS Anthony, Consecuencias de la modernidad, Madrid, Alianza Editorial, 1993.

HABERMAS Jürgen, Teoría de la acción comunicativa I y II, (Trad. castellana de M. Jimenez de Theorie des kommunikativen Handelns, Frankfurt am Main, Suhrkamp Verlag, 1981) Madrid, Taurus, 1987, tomo I y II.

--- Pensamiento postmetafísico, (traducción castellana de M. Jiménez Redondo de Nachmetaphysisches Denken, Frankfurt am Main, Suhrkamp Verlag, 1988), Madrid, Taurus, 1990.

JERVOLINO Doménico, «La traduzione come problema filosofico», en Studium, 1 (2005), pp. 59-67. 
LADRIÈRE Jean, "Le destin de la raison et les tâches de la philosophie», en Vie Sociale et Destinée, Namur, Éd. Duculot, 1973, pp. 19-37.

LÓPEZ Sirio, Fundamentos lógico-lingüísticos da ética argumentativa, São Leopoldo, Nova Harmonia, 2003.

MAESSCHALCK Marc, Normes et contextes. Les fondements d'une pragmatique contextuelle, Hildesheim - Zürich - New York, Georg Olms, 2001.

MICHELINI Dorando, Globalización, interculturalidad y exclusión. Ensayos ético-políticos, Río Cuarto, Ediciones del Icala, 2002.

PICOTTI DINA, "Sobre "Filosofía Intercultural"», en Stromata 52, (1996) 289-298.

PIZZI Jovino, El mundo de la vida. Husserl y Habermas, Santiago, Ediciones UCSH, 2005.

RICOEUR Paul, A l'École de la Phénoménologie, Paris, Vrin, 1986.

--- Del Texto a la Acción, (Trad. castellana de Pablo Corona), México, FCE, 2002, segunda edición.

--- Le Juste 2, Paris, Éd. Esprit, 2001.

SALAS Ricardo, "Conquista, traducción y lenguaje misionero en el siglo XVI», en Revista Mapocho 32, (1992) 209-224.

--- Ética Intercultural. Ensayos de una ética discursiva para contextos culturales conflictivos. (Re)Lecturas del pensamiento latinoamericano, Santiago de Chile, UCSH, 2003.

--- «Bases discursivas para una ética intercultural» en Revista Polylog. Foro para filosofía intercultural 5 (2004). Online: http://them.polylog.org/5/asres.htm

SAN MARTIN Javier (Ed.), Sobre el concepto de mundo de la vida, Madrid, UNED, 1994.

TRIGO Pedro, «Establecer una sociedad multiétnica y pluricultural en un estado de justicia. El diálogo intercultural en Venezuela», en Revista ITER 28, (2002) 63-89. 